\title{
Treating Granulomatosis With Polyangiitis Presenting as Mastitis With Rituximab
}

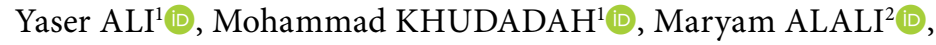 \\ Smiley GEORGE ${ }^{3}$, Ahmad ABDULSALAM $^{4}$ \\ ${ }^{1}$ Department of Rheumatology, Mubarak Al-kabeer Hospital, Jabriya, Kuwait \\ ${ }^{2}$ Department of Internal Medicine, Mubarak Al-kabeer Hospital, Jabriya, Kuwait \\ ${ }^{3}$ Department of Pathology, Mubarak Al-kabeer Hospital, Jabriya, Kuwait \\ ${ }^{4}$ Department of Physical Medicine and Rehabilitation, Physical Medicine and Rehabilitation Hospital, Andalous, Kuwait
}

Granulomatosis with polyangiitis (GPA) is a rare and complex immune mediated disease, which is a part of the anti-neutrophil cytoplasmic antibodies (ANCA) associated vasculitis. ${ }^{1}$ It is characterized by necrotizing granulomatous inflammation of vascular tissue or perivascular area. ${ }^{1}$ The disease has a spectrum of manifestations. However, involvement of the breast as an initial presentation of GPA has been described only a few times in the literature..$^{2,3}$ Thus, no clear line of management has been established with this rare presentation.

A 26-year-old female patient presented with erythematous and tender left breast tissue. After some preliminary investigations, magnetic resonance imaging was sought revealing mastitis with regional heterogeneous non-mass enhancement, associated with thickened overlying skin tissue and edematous, tethered pectoralis muscle, and left axillary lymph nodes. The patient underwent an elective left breast lumpectomy and histopathology of the breast tissue showed discrete and confluent granulomatous lobulitis composed of epithelioid histiocytes, Langhans giant cells and lymphocytes, plasma cells with central abscess formation representing florid suppurative-chronic and granulomatous mastitis, with no evidence of infection, tuberculosis or malignancy (Figure 1).

Further history revealed that she had recurrent problems for shortness of breath, wheezes, dry cough and non-allergic sinusitis, and epistaxis in the past seven years. The patient also noted bilateral thigh pain. Her laboratory results showed positive proteinase 3-ANCA and negative autoimmune serology and inflammatory markers. A nerve conduction study was preformed showing axonal neuropathy, and the diagnosis of mononeuritis multiplex was established. Magnetic resonance imaging of the brain and spine were unremarkable.

A positron emission tomography-computed tomography was performed that showed a left anterior lung inflammatory lesion with no evidence of metastasis or other active lesions. With the findings of mononeuritis multiplex, breast tissue biopsy, positive proteinase 3-ANCA, and respiratory symptoms, the diagnosis of GPA was reached.

Received: March 26, 2018 Accepted: March 27, 2018 Published online: May 03, 2018

Correspondence: Ahmad Abdulsalam, MD. Department of Physical Medicine and Rehabilitation, Physical Medicine and Rehabilitation Hospital, Andalous, Kuwait. Tel: +96597923190 e-mail: dr.ahmad.j.abdulsalam@gmail.com 


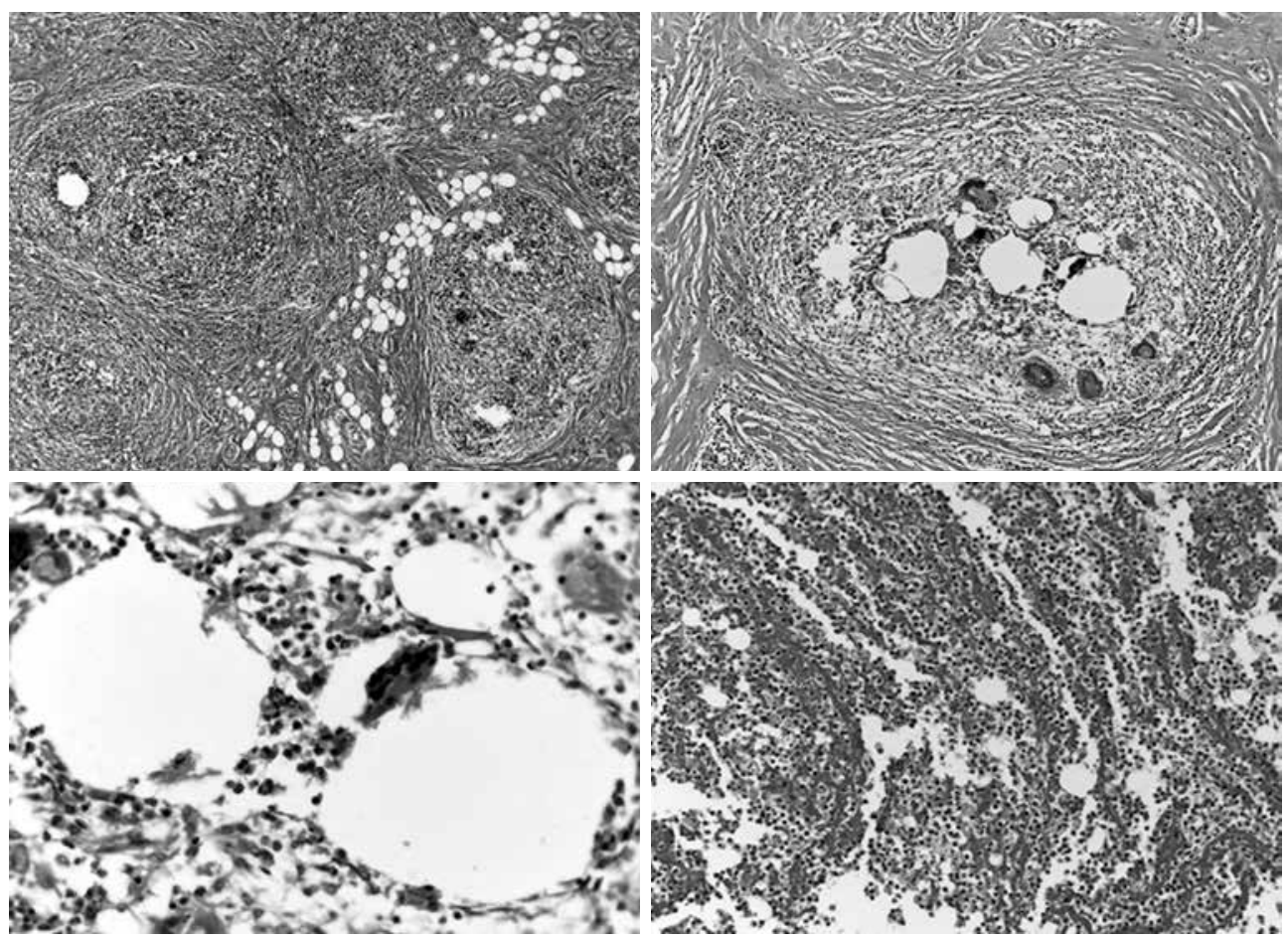

Figure 1. Breast tissue with multiple epithelioid and lobulocentric epithelioid granulomas containing multinucleated giant cells and empty spaces rimmed by neutrophils can be appreciated. Some abscess formation and inflammation are also shown (H-E 40× and 100×, respectively).

She was started on prednisolone $1 \mathrm{mg} / \mathrm{kg}$ for eight weeks. In addition, she was started on $500 \mathrm{mg}$ rituximab weekly for four weeks. After a five-month follow-up, she showed marked clinical response with no relapses. A second cycle of rituximab was to be initiated in one-month time.

Granulomatosis with polyangiitis presenting with mastitis is a rare feature and a high index of suspicion is required to reach the diagnosis. ${ }^{4}$ The best diagnostic tool is histopathology, supported by specific laboratory investigations, as the imaging findings are non-specific. ${ }^{4,5}$ Treatment with rituximab is an alternative option for physicians to consider for younger patients, particularly in the presence of other systemic manifestations. To our knowledge, the use of rituximab in GPA presenting with mastitis has not been documented in the literature. Hence, further research is essential to project the efficacy of this treatment.

\section{Declaration of conflicting interests}

The authors declared no conflicts of interest with respect to the authorship and/or publication of this article.

\section{Funding}

The authors received no financial support for the research and/or authorship of this article.

\section{REFERENCES}

1. Allende DS, Booth CN. Wegener's granulomatosis of the breast: a rare entity with daily clinical relevance. Ann Diagn Pathol 2009;13:351-7.

2. Neralic-Meniga I, Ivanovi-Herceg Z, Mazuranic I, Puljic I, Zekan M, Gorecan M, et al. Wegener's granulomatosis of the breast. Wien Klin Wochenschr 2006;118:120-3.

3. Korkut E, Akcay MN, Karadeniz E, Subasi ID, Gursan N. Granulomatous Mastitis: A Ten-Year Experience at a University Hospital. Eurasian J Med 2015;47:165-73.

4. Jordan JM, Rowe WT, Allen NB. Wegener's granulomatosis involving the breast. Report of three cases and review of the literature. Am $\mathrm{J}$ Med 1987;83:159-64.

5. Kubaisi B, Abu Samra K, Foster CS. Granulomatosis with polyangiitis (Wegener's disease): An updated review of ocular disease manifestations. Intractable Rare Dis Res 2016;5:61-9. 